\title{
Using Topographic Advantages in Formulating a Strategy to Access Ore Bodies at Ban Phuc Nikel Mine
}

\author{
Hung Nguyen Phi ${ }^{1, *}$, and Thang Pham Duc ${ }^{2}$ \\ ${ }^{1}$ Hanoi University of Mining and Geology \\ ${ }^{2}$ Quang Ninh University of Industry, Vietnam
}

\begin{abstract}
There are various types of underground mining that are categorized based on the kind of shafts used, the technique of extraction and the process used to get to a deposit. Development mining is composed of excavation almost entirely in (non-valuable) waste rock in order to gain access to the orebody. To start the mining, the first step is to make the path to go down. Development, the work of opening a mineral deposit for exploitation is performed. With it begins the actual mining of the deposit. Access to the deposit must be gained either by stripping the overburden, which is the soil and/or rock covering the deposit,to expose the nearsurface ore for mining or by excavating openings from the surface to access more deeply buried deposits to prepare for underground mining. The type of underground mining technique used is typically based on the geology of the area, especially the amount of ground support needed to make mining safe. When using to exploit ore body by underground mining method, the textbook guide in universities of Vietnam had had 4 main strategies include: access by horizontal tunnel lines, access by incline shaft, vertical shaft and combination of above access method. In this study, we developed a solution outside of four above approaches, to take advantage of the topography, transport potential energy, and advantages when constructing sloped incline, backward from outside to inside.
\end{abstract}

\section{Introduction}

\subsection{Geographic location and topographic characteristics}

Ban Phuc nikel mining (BPNM) has an approved mining licence located over the Ban Phuc Deposit $160 \mathrm{~km}$ west of Hanoi in Son La Province, in the northwest of the Socialist Republic of Vietnam. The selected mine plan has been developed in close consultation with the geotechnical consultants to produce a simple mining method, whereby a number of areas of the orebody can be in production at one time, therefore providing a flexible mine to meet the needs of the production profile. The Ban Phuc deposit is located within rugged terrain of the mountainous areas in the north-west of Vietnam. The steep-sided Da River

\footnotetext{
*Corresponding author: hunguni@gmail.com
} 
Valley traverses the region in a general south-easterly direction. On the northern side, steep mountainous country rises to about 1,200 m near Hong Ngai. On the south side of the Da River similar mountainous country rises to $1,520 \mathrm{~m}$. Second order streams with catchments of 20 to $200 \mathrm{~km} 2$ drain north and south into the Da River and commonly have small alluvial flats in their lower reaches. Third and fourth order streams in steep V-shaped valleys at close intervals drain into the second order streams and directly into the Da River. This closely spaced drainage system results in steep slopes of $30^{\circ}$ to $45^{\circ}$, which are further exaggerated in areas of calcareous rocks, where upstanding massifs and karst topography occur, especially in the east and southwest $[1,2,3,4]$.

Ban Phuc project area to exploit copper, nickel, cobalt and associated minerals; development of mines to exploit copper, nickel, cobalt and the associated minerals within. Exploit area scale $150 \mathrm{~km} 2$ at Ban Phuc mine area.

The Ban Phuc deposit is located within rugged terrain in mountainous areas in the north-west of Vietnam. The topography of the project area ranges between steeply sloping hills with elevations between 100 and $550 \mathrm{~m}$ above sea level and narrow valleys with few flat areas.

Mining license boundaries are defined by the location of corner claim pegs with approximate coordinates based on GPS readings recorded in claim documentation.

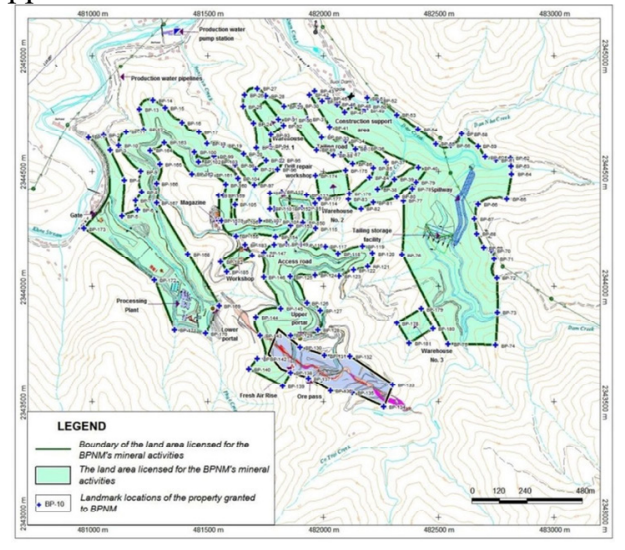

Fig. 1. Licenced areas

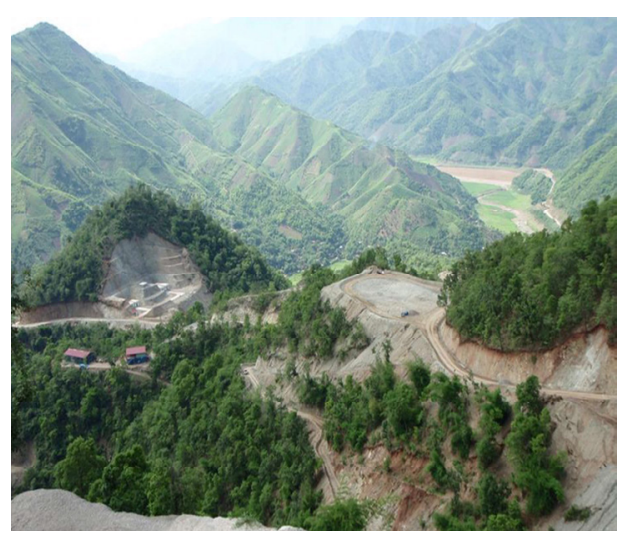

Figure 2. Ban Phuc Nickel area overview looking to northwest explosives magazine in centre left and upper ROM pad centre right.

\subsection{Regional Geology}

The concession area lies in the Song Da rift, a major crustal suture zone, which is part of a broader northwest trending corridor of deep continental rifting known as the Red River Fault Zone (Figure 3). This feature acted as both a rift and collision zone between the South China Continental Plate to the north-east and the Indochina Plate to the south-west and is recognized as a rare case of where faulting has extended the entire thickness of the continental crust to the base of the lithosphere.

The concession area lies in the Song Da rift, a major crustal suture zone, which is part of a broader northwest trending corridor of deep continental rifting known as the Red River Fault Zone. This feature acted as both a rift and collision zone between the South China Continental Plate to the north-east and the Indochina Plate to the south-west and is recognized as a rare case of where faulting has extended the entire thickness of the continental crust to the base of the lithosphere. Within this faulted corridor, and in the Ta Khoa region, an anticline of Devonian limestones and terrigenous sediments is overlain by an unusual Permian-Triassic flood-basalt suite. The Devonian sequence is intruded by numerous ultramafic intrusions of compositions ranging from high-Mg gabbro, pyroxenite, 
and peridotite to dunite. The intrusions are interpreted as sub-volcanic dykes and sills representing feeders for the overlying volcanic suite. Many of the intrusive have associated sulfides mineralization. Ban Phuc is emplaced close to the axial zone of the Ta Khoa Shoa anticline and is the only intrusive to date to have a quantified $\mathrm{Ni}-\mathrm{Cu}$ sulfide resource. The Ban Phuc intrusion is one of the larger ultramafic bodies in the region with dimensions of $940 \mathrm{~m}$ by $220-420 \mathrm{~m}$, an outcrop area encompassing $0.25 \mathrm{~km} 2$ and, a preserved depth of up to $470 \mathrm{~m}$ below surface. The intrusion is elongate with a north-westerly trend corresponding to the strike of the Devonian meta-sedimentary host rocks. It has intruded along the trend of a discontinuous unit of crystalline limestone. At its wider north-western edge, only the flat lying base is preserved. The intrusion narrows and deepens to the southeast where it has an oval cross-section dipping steeply northeast and roughly concordant with the enveloping metasediments. A locally discordant contact with metasediments confirms the body is intrusive and not extrusive as in nickel deposits of the komatiite type.

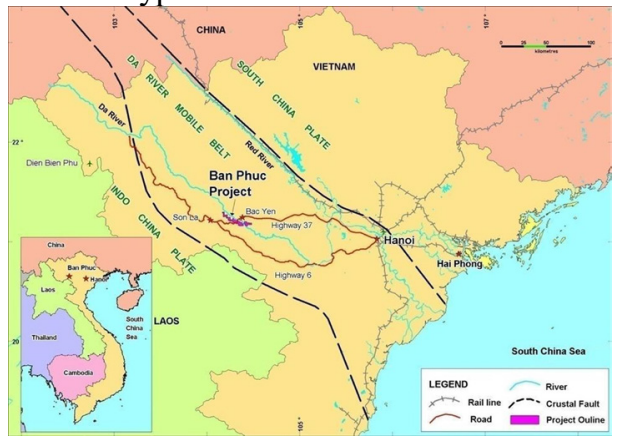

Fig. 3. Regional geological setting

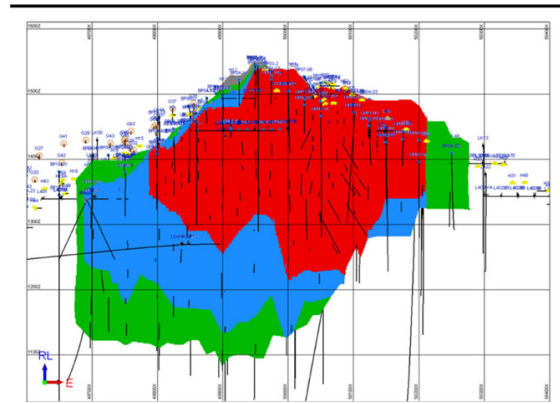

Figure 4. Looking North View on Ban Phuc MSV resource model classification

Massive Sulphide Vein (MSV) Type Mineralization contains a number of minerals as follows (relative percentages are given in parentheses): pyrrhotite $(70 \%)$, pentlandite $(10 \%)$, chalcopyrite $(5 \%)$, magnetite $(4 \%)$, pyrite $(3 \%)$, violarite $(2.5 \%)$, siderite, ilmenite, sphalerite, galena $(<1 \%)$, non-Opaques $(5 \%)$. Pyrrhotite occurs in $1-3 \mathrm{~mm}$ grains with fine exsolutions of pentlandite. Pentlandite occurs in granular masses with a grain size of $0.06-$ $2 \mathrm{~mm}$, and as fine inclusions in pyrrhotite. Chalcopyrite forms irregular grain aggregates up to $3 \mathrm{~mm}$ in size, and inclusions in pyrrhotite.

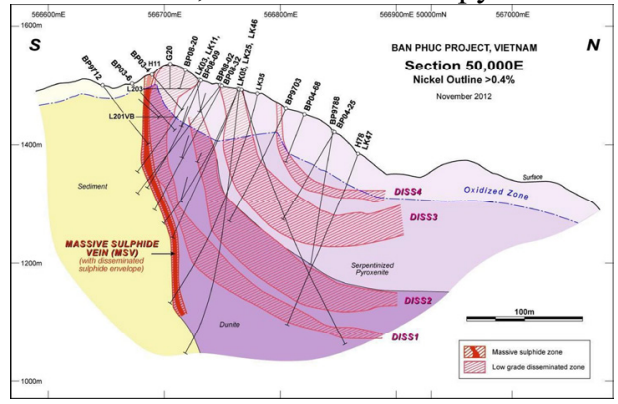

Fig. 5. Ban Phuc mineralization styles

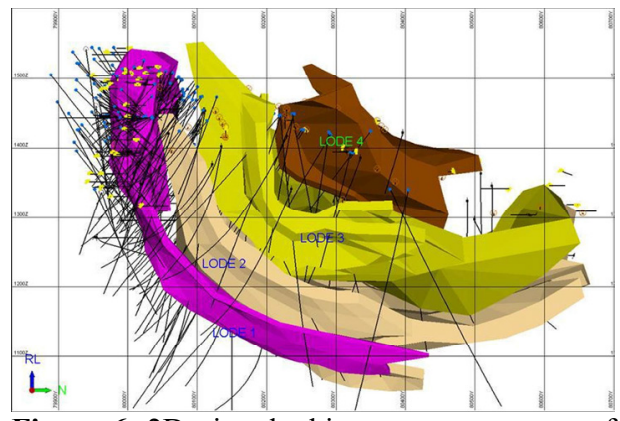

Figure 6. 2D view looking west on extents of DISS mineralized lodes with drill hole collars. 


\section{Establishing the approach and exploit method}

\subsection{Establishing the approach}

The characteristics of topography of Ban Phuc mine area below:

On the northern side, steep mountainous country rises to about 1,200 m near Hong Ngai. On the south side of the Da River similar mountainous country rises to $1,520 \mathrm{~m}$. Second order streams with catchments of 20 to $200 \mathrm{~km}^{2}$ drain north and south into the Da River and commonly have small alluvial flats in their lower reaches. Third and fourth order streams in steep V-shaped valleys at close intervals drain into the second order streams and directly into the Da River. This closely spaced drainage system results in steep slopes of $30^{\circ}$ to $45^{\circ}$, which are further exaggerated in areas of calcareous rocks, where upstanding massifs and karst topography occur, especially in the east and southwest.

The Ban Phuc deposit is located within rugged terrain in mountainous areas in the north-west of Vietnam. The topography of the project area ranges between steeply sloping hills with elevations between 100 and $550 \mathrm{~m}$ above sea level and narrow valleys with few flat areas.

Followed the characteristics Ban Phuc nickel mine, There are two types of exploitation considered open pit and underground mining. Thus, open pit method get a financial effect, otherwise has the disadvantage of breaking up the landscape and environment structure more than underground mining, especially waste rock and soil. This study considered the underground method only.

\subsection{Access ore body}

To prepare a Mineral Reserve estimate for underground mining by "up-hole retreat benching, without backfill". The approach taken to prepare the estimate, based on geological and resource data provided outlined below. The interpreted lens is narrow in places, i.e. $1.2 \mathrm{~m}$ but the widest zones are approximately $9 \mathrm{~m}$ to $10 \mathrm{~m}$. To use a $3.0 \mathrm{~m}$ minimum mining width extraction wireframe constructed. In an effort to reduce dilution and increase the mining grade, $2.5 \mathrm{~m}$ wide extraction wireframes. Figure 7 to Figure 9 below shows the $2.5 \mathrm{~m}$ minimum mining width wireframes, which do not include the nearsurface oxide zones $[5,6]$.

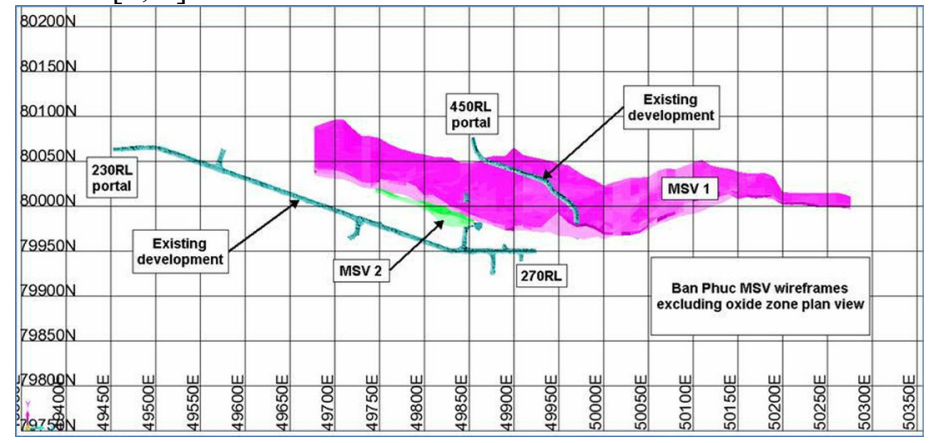

Fig. 7. Option 1: Approach by inclined with $18^{0}$ 


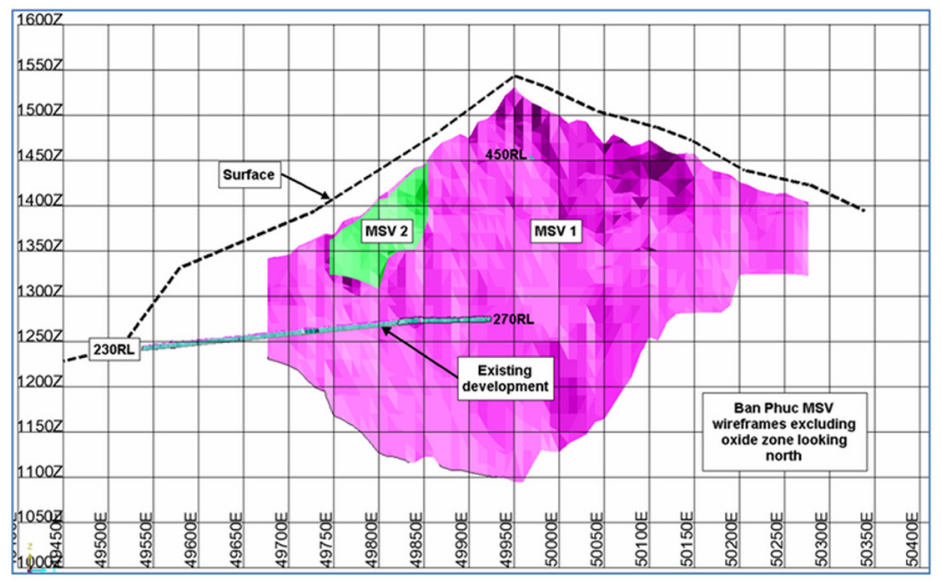

Fig. 8. Option 2: Access by inclined with angle $-18^{0}$ (looking north)

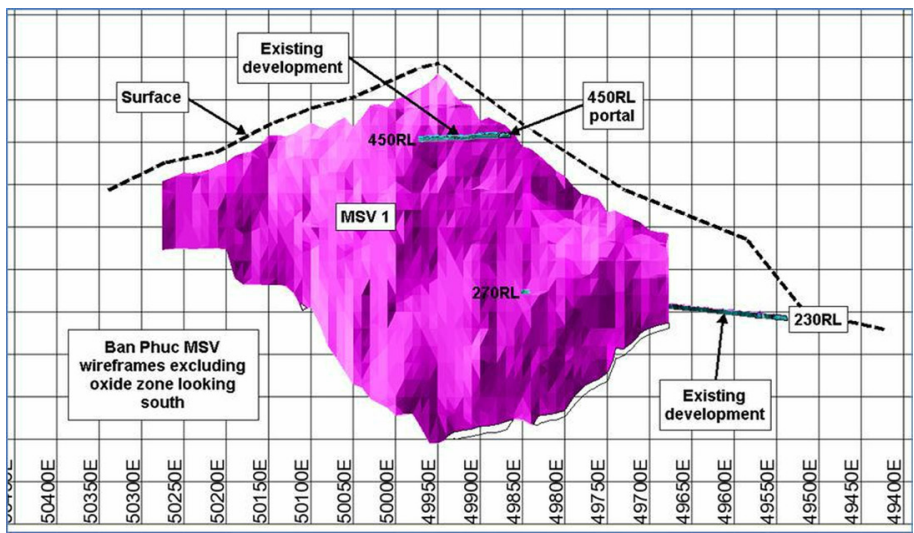

Fig. 9. Ban Phuc MSV wireframes (looking south)

\section{Mining method}

After application of the minimum mining-width to the resource, processing and economic factors were applied as follows. The selected mining method is "up-hole retreat benching, without backfill". This method was chosen because of the following factors: Simple mining method; Lower operating and capital cost method to those involving backfill; Top down method, which enables earlier access to ore.

The following diagram (Figure 10) indicates how the method will be used at Ban Phuc.

Referring to the diagram, the method is as follows:

The ore body will be accessed via crosscuts developed from a central decline/incline system at $20 \mathrm{~m}$ vertical intervals.

$4.5 \mathrm{~m}$ high sill drives or "sills" will be mined along the ore body from the crosscut on a $20 \mathrm{~m}$ (floor to floor) vertical spacing.

The sills will be mined to $4.0 \mathrm{~m}$ minimum width and to a maximum of $6.0 \mathrm{~m}$, ground conditions permitting. The orebody width ranges from $2.5 \mathrm{~m}$ to $9 \mathrm{~m}$, for $2.5 \mathrm{~m}$ WF MSV1 and $2.5 \mathrm{~m}$ to $10 \mathrm{~m}$ for the $2.5 \mathrm{~m}$ WF MSV2.

Starting from the far end, either east or west, the orebody will be drilled out with nominal $64 \mathrm{~mm}$ diameter blast holes. The holes, approximately $16 \mathrm{~m}$ long $(15.5 \mathrm{~m}$ vertical dimension) will be drilled upwards towards the next sublevel above. 
A suitable production drill rig would drill an up-hole longhole rise ("LHR") and cut-off slot out to the width of the ore body.

Parallel holes will be drilled in "rings" back from the LHR, to the extent of the predicted stable span. To aid in charging and firing these rings will be angled upwards toward the LHR.

This will form a drilled out panel. This pattern of LHR and rings is repeated back to the access crosscut.

Once production of the lift above has been completed in that area, the up-hole LHR can be fired. Firing of rings would follow as required with the size of the blasts tailored to suit the ground conditions in the bench.

Load-haul-dump ("LHD") units will load or "muck" the ore out of the stope.

Mining the sills to a $4 \mathrm{~m}$ minimum width should enable ease of mucking.

Conventional mucking could be used whilst the brow is closed.

Once the brow is opened, it is proposed that tele-remote mucking be used. Pillars of various sizes, as shown in the figure above, will be left in between the panels to stabilize the walls of the void, as the void is not filled.

The sizes of crown pillars in between vertically adjacent production regions

The production rate of each panel - a group of benches between crown pillars - depends largely upon the width of the orebody; wide areas yield higher tonnes per metre of strike, so mucking in between firings will be more continuous. Narrow areas may yield only enough fired ore for part of a shift, after which charging and firing would need to be undertaken again.

The use of crown/sill pillars means that any failures of stope walls or backs will be arrested by the crown/sill pillar left at the top of the next panel. This will eliminate dilution from previously mined areas progressing to the next panel, although at the expense of lower ore recovery due to more ore being left in pillars $[3,6,7,8]$.

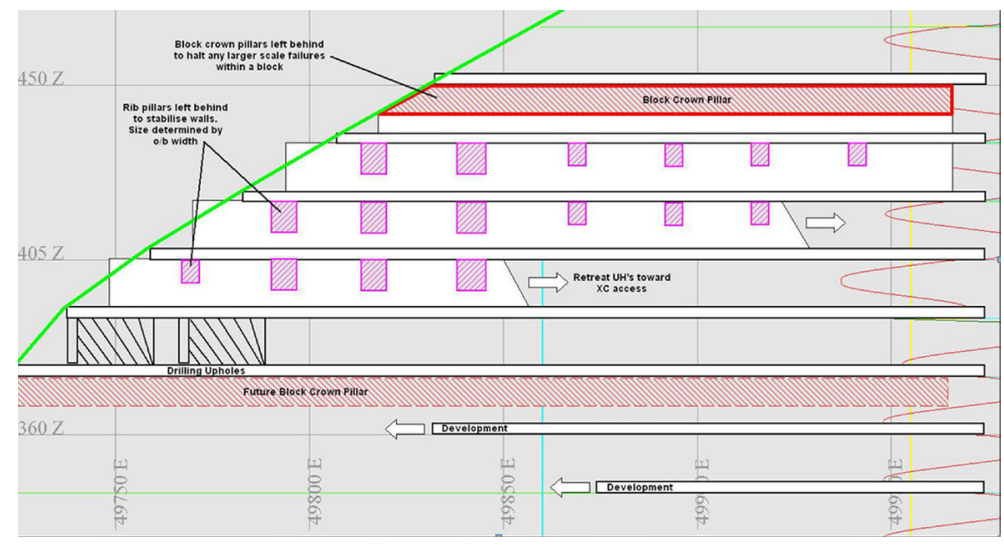

Fig. 10. Up-hole retreat benching 


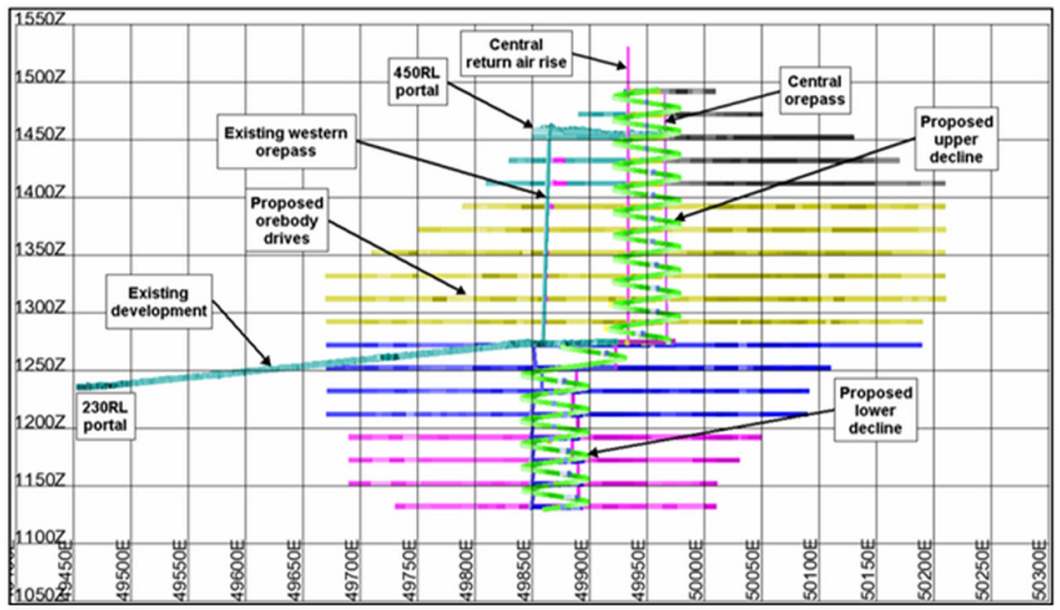

Fig. 11. Four Areas of exploit schedule

A $20 \mathrm{~m}$ vertical stope spacing with discontinuous rib pillars every $20 \mathrm{~m}$ along strike is likely to require thickening of one or more crown and rib pillars and a reduction in stope strike length in some areas. The suggested crown pillar thickness is $7.8 \mathrm{~m}$ and rib pillar dimension is $40 \mathrm{~m}^{2}$.

The crown pillar for $20 \mathrm{~m}$ sub-interval layout will require a $30 \%$ increase in the crown pillar thickness. The resultant thickness is $6 \mathrm{~m} \times 1.3=7.8 \mathrm{~m}$.

The rib pillars will need to be increased by $10 \%$. Therefore the rib pillar area is $36 \mathrm{~m} 2$ $\mathrm{x} 1.1=40 \mathrm{~m}^{2}$.

With the crown pillars allocated to 430,310 and $210 \mathrm{RLs}$, the mine is divided into 'Production Areas', whereby each Area can be mined independently of others to help achieve the required production rate. These 4 Areas are shown in Figure 11 below. The intention is to mine each block from the top bench down. Table 1 is a summary of the development metres for this application.

Table 1. Mechanical properties of rock mass used in numerical modelling

\begin{tabular}{|l|c|}
\hline \multicolumn{1}{|c|}{ Development type } & Metres \\
\hline Decline development (waste) & 2,791 \\
\hline Access development (waste) & 1,095 \\
\hline Stockpile bays (waste) & 449 \\
\hline Other (waste) & 1,010 \\
\hline Sill development (ore) MSV1 east & 4,083 \\
\hline Sill development (ore) MSV1 west & 3,605 \\
\hline Sill development (ore) MSV2 east & 406 \\
\hline Total Lateral development & 13,439 \\
\hline Total Vertical development & 723 \\
\hline
\end{tabular}




\section{Conclusions}

This exercise indicates that the old rule of thumb in BanPhuc mining area, that the economic changeover point between two types of vertical shafts is $18^{0}$ and $-18^{0}$. Noticeably, as tonnage and depth increase, the shaft hoisting systems becomes more attractive. As with any new project, the mining engineer should validate the changeover topography for their specific project as operating costs, will vary from operation to operation.

\section{References}

1. Nguyen Phi Hung, Tran Xuan Ha, FS and Ban Phuc mining design (CTS, Hanoi, 2006)

2. Nguyen Phi Hung, Tran Xuan Ha, Dao Ngoc Hoang, FS and Ban Phuc mining design (CTS, Hanoi, 2012)

3. Do Manh Phong, Ore Underground Exploitation (CTS, Hanoi, 2002)

4. Nguyen Phi Hung, Underground ore mining technological process (CTS, Hanoi, 2016)

5. The mine planning for the Massive Sulphide Vein (MSV) zone at the Ban Phuc Nickel Mine (BPNM) in Vietnam was completed by Australian Mine Design and Development Pty Ltd (AMDAD, Melbourn, 2012)

6. S.M. Rupprecht, Mine development - access to deposit, The Southern African Institute of Mining and Metallurgy Platinum (2012).

7. W. S. Dunbar, Basics of Mining and Mineral Processing, University of British Columbia (DTRV, Remment, 2012)

8. H. Hamrmin, Underground mining methods and applications (SMSI, Stockholm 2012) 